\title{
Novel side-by-side metal stent placement for recurrent hepatic hilar obstruction after placement of multiple metal stents
}

Endoscopic re-intervention following placement of multiple self-expandable metal stents (SEMSs) is challenging [1 3]. A suitable re-intervention for malignant hilar biliary obstruction (MHBO) is not available. Plastic stents are used for re-intervention following placement of multiple SEMSs, but advancing the plastic stents through the mesh of the SEMS is difficult. This report describes successful side-by-side (SBS) metal stent deployment for recurrent MHBO after placement of SEMSs.

A 69-year-old man underwent endoscopic multistent drainage $(8 \mathrm{~mm} \times 8 \mathrm{~cm}$ and $8 \mathrm{~mm} \times 6 \mathrm{~cm}$; BileRush Selective; Piolax, Kanagawa, Japan) using a partial stent-in-stent (SIS) technique for MHBO due to a recurrent lesion after left lob-
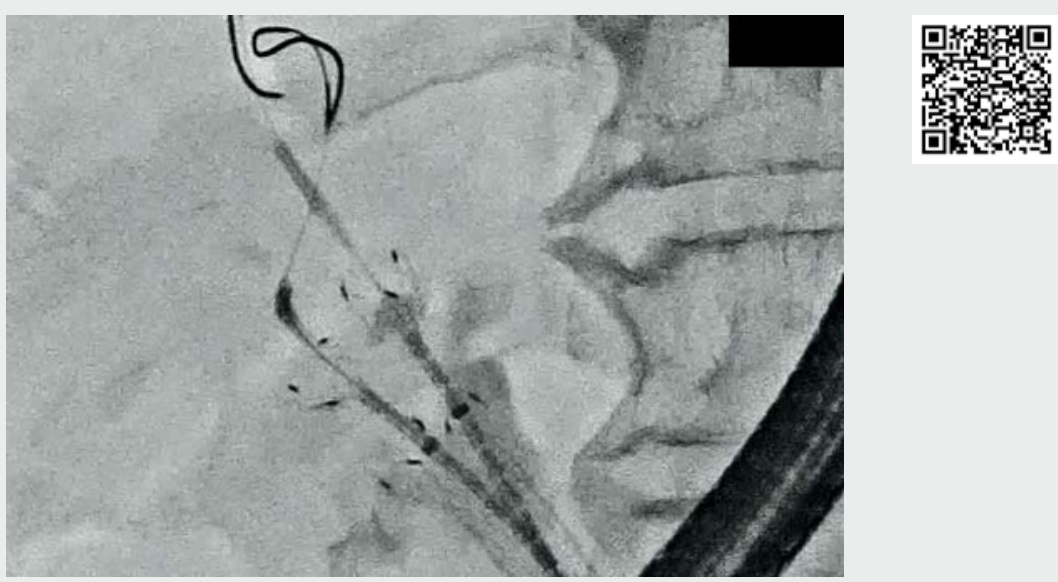

Video 1 Simultaneous side-by-side self-expandable metal stent (SEMS) placement as reintervention for occlusion of SEMSs previously placed using the stent-in-stent technique.
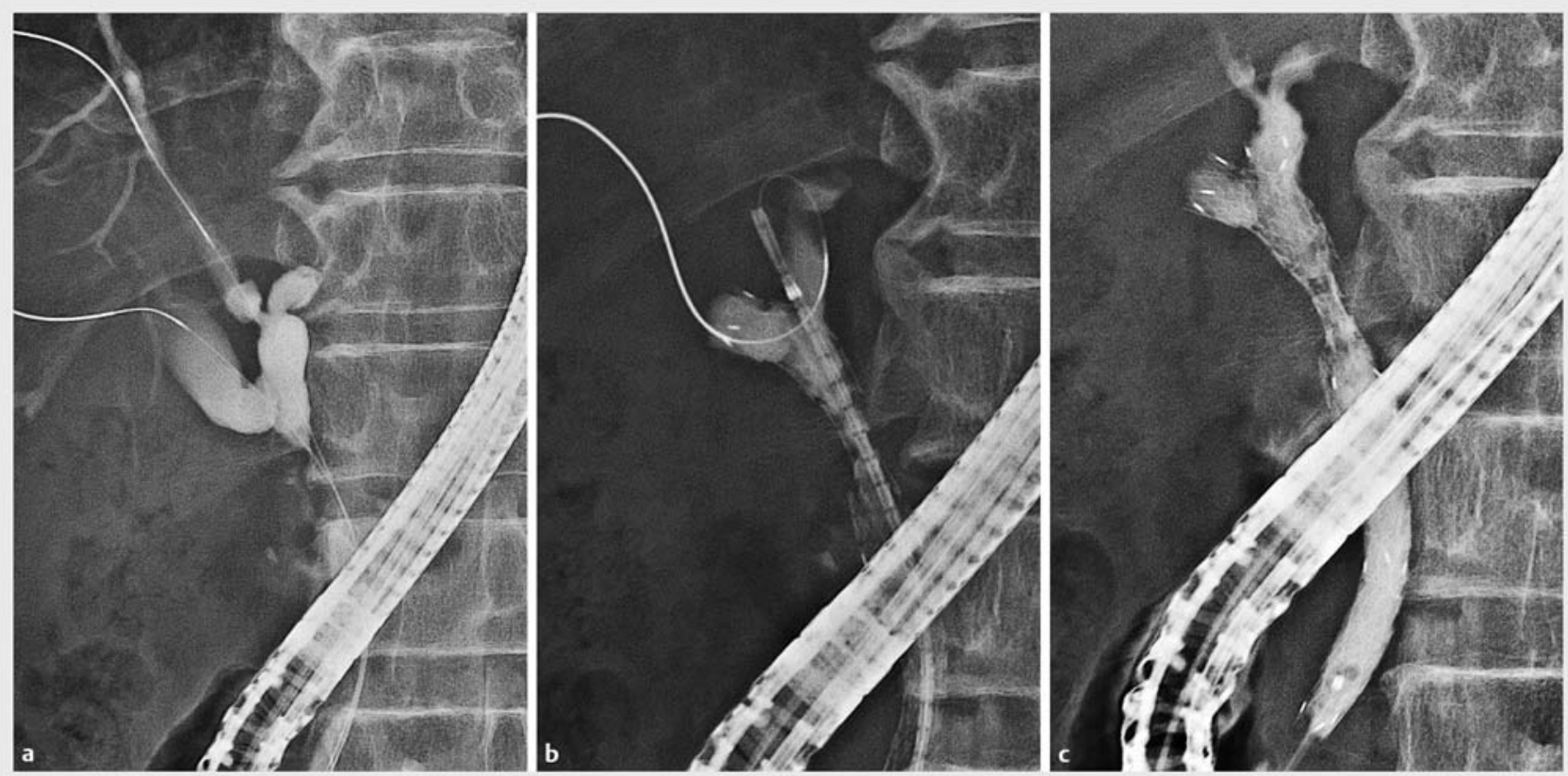

- Fig. 1 Endoscopic images of the initial drainage by partial stent-in-stent technique showing: a two 0.025 -inch guidewires inserted into the dilated anterior and posterior branches: $\mathbf{b}$ the second uncovered self-expandable metal stent (SEMS; $8 \mathrm{~mm} \times 6 \mathrm{~cm}$ ) being placed into the anterior branch through the mesh of the first uncovered SEMS $(8 \mathrm{~mm} \times 8 \mathrm{~cm})$ that had been placed in the posterior branch; $\mathbf{c}$ appearance after placement of the two stents. 

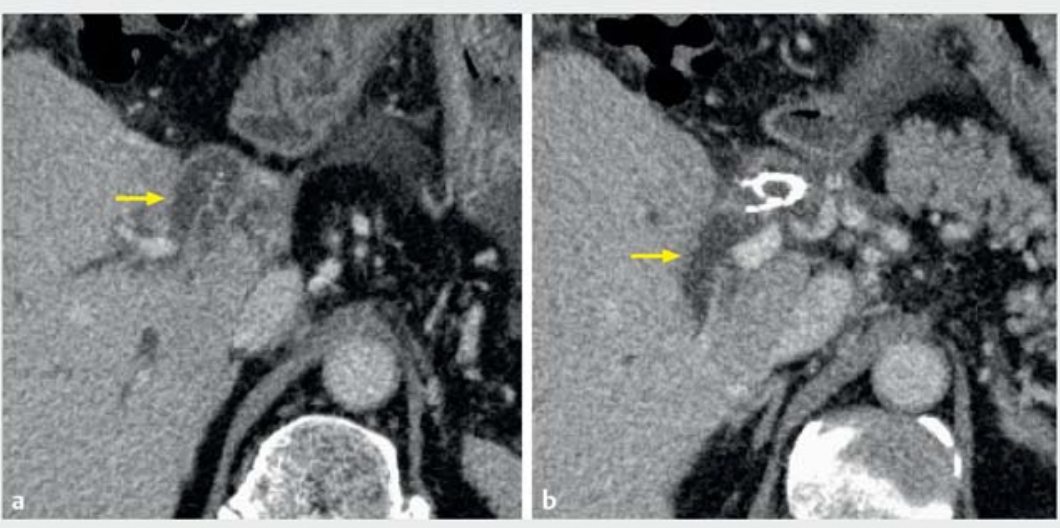

- Fig. 2 Abdominal contrast-enhanced computed tomography scan showing recurrent hilar obstruction due to tumor ingrowth into the stent with dilatation of: a the anterior branch; b the posterior branch.
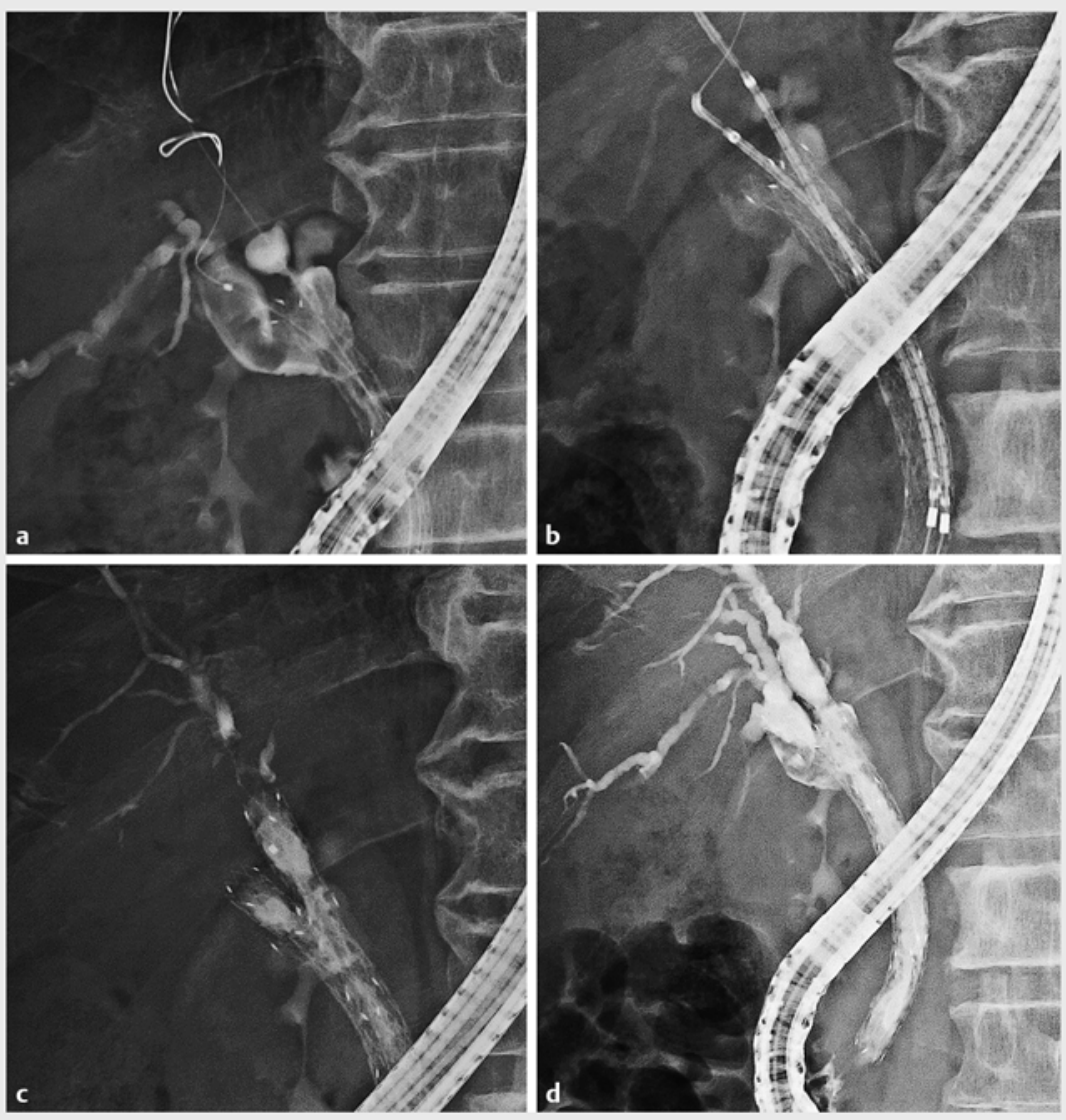

Fig. 3 Endoscopic retrograde cholangiopancreatography images of simultaneous side-byside self-expandable metal stent (SEMS) placement as re-intervention for occluded SEMSs showing: a recurrent hilar obstruction due to tumor ingrowth and overgrowth; $\mathbf{b}$ the two delivery systems for the $8-\mathrm{mm} \times 8-\mathrm{cm}$ uncovered SEMSs that were inserted simultaneously over the guidewires; $\mathbf{c}, \mathbf{d}$ the two SEMSs after their simultaneous deployment. ectomy for left intrahepatic cholangiocarcinoma ( $\mathbf{F i g} . \mathbf{1})$. His obstructive jaundice recurred 7 months later. A contrast-enhanced computed tomography (CT) scan ( $\triangleright$ Fig. 2 ) and endoscopic retrograde cholangiography (ERC) ( $\vee$ Fig. 3 a) revealed recurrent hilar obstruction due to tumor ingrowth and overgrowth.

Endoscopic re-intervention was performed. Two 0.025-inch guidewires (VisiGlide 2; Olympus, Tokyo, Japan) were inserted into the dilated anterior and posterior branches, and two lasercut SEMSs $(8 \mathrm{~mm} \times 8 \mathrm{~cm}$; BileRush Selective; Piolax) with 5.7- $\mathrm{Fr}$ delivery systems were simultaneously inserted over the guidewires without balloon dilation of the stent mesh ( $\vee$ Fig. $\mathbf{3} \mathbf{b}$; $\vee$ Video $\mathbf{1}$ ). The stents were then deployed in the optimal positions using the SBS technique ( Fig. 3c, d). $\triangleright$ Fig. 4 shows the post-insertion CT images. His total bilirubin level improved from $4.4 \mathrm{mg} / \mathrm{dL}$ to $1.7 \mathrm{mg} / \mathrm{dL}$ within 14 days. Three months later, he succumbed to underlying disease but without experiencing occlusion of the SEMSs.

Re-intervention using SBS placement of metal stents has two advantages over plastic stents. First, the thin SEMS delivery systems are simpler to advance and track, and easily penetrate the mesh for stent deployment. Second, SEMSs have longer patency than plastic stents [1]. This is the first report of the placement of simultaneous SBS SEMSs for re-intervention in recurrent MHBO following placement of multiple SEMSs. This innovative, efficacious method may be considered after the placement of multiple SEMSs.

Endoscopy_UCTN_Code_TTT_1AR_2AZ

\section{Acknowledgment}

This work was supported in part by The National Cancer Center Research and Development Fund (31-A-13) and by a grant from The Japanese Foundation for Research and Promotion of Endoscopy (JFE).

\section{Competing interests}

The authors declare that they have no conflict of interest. 

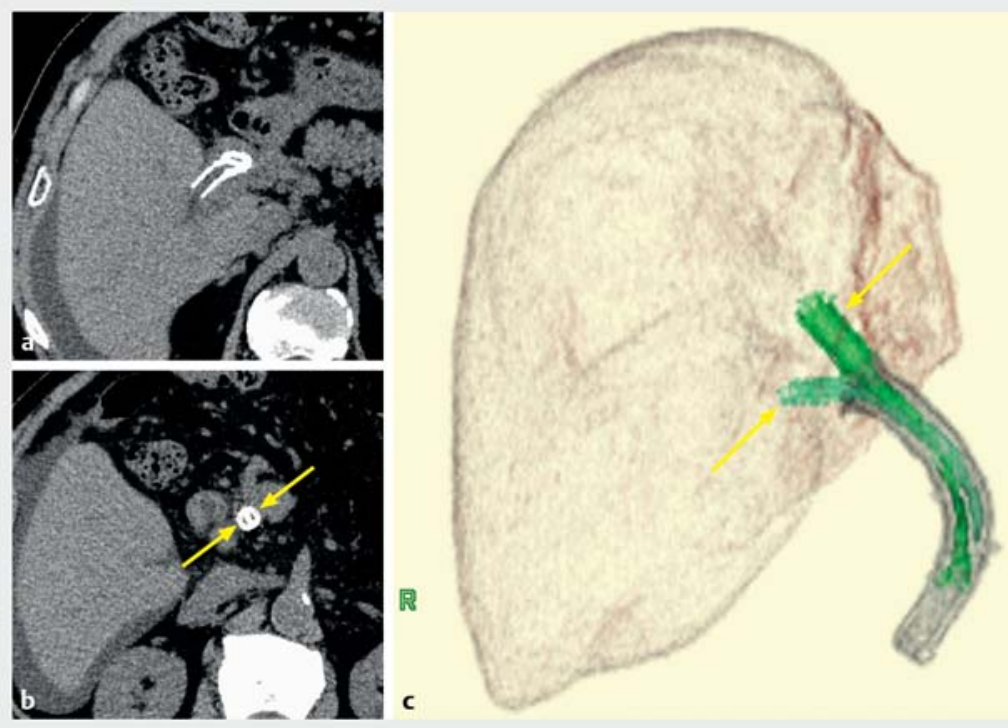

- Fig. 4 Computed tomography (CT) scan images after simultaneous endoscopic side-byside (SBS) placement of two uncovered self-expandable metal stents (SEMSs) showing: a the SEMSs in the anterior and posterior segments; $\boldsymbol{b}$ the SBS SEMSs (yellow arrows); $c$ a reconstructed CT image of the SBS SEMSs (yellow arrows) positioned in the SEMSs previously deployed using the stent-in-stent technique.

The authors

Yoshikuni Nagashio', Susumu Hijioka ${ }^{1}$, Yuya Kanai $^{2}$, Akihiro Ohba ${ }^{1}$, Yuta Maruki ${ }^{1}$, Takuji Okusaka', Yutaka Saito ${ }^{3}$

1 Department of Hepatobiliary and Pancreatic Oncology, National Cancer Center Hospital, Tokyo, Japan

2 Department of Radiological Technology, National Cancer Center Hospital, Tokyo, Japan

3 Endoscopy Division, National Cancer Center Hospital, Tokyo, Japan

\section{Corresponding author}

\section{Susumu Hijioka, MD, PhD}

Department of Hepatobiliary and Pancreatic Oncology, National Cancer Center Hospital, 5-1-1 Tsukiji, Chuo-ku, Tokyo 104-0045, Japan

Fax: +81-3-35423815

shijioka@ncc.go.jp

\section{References}

[1] Inoue T, Naitoh I, Okamura F et al. Reintervention for stent occlusion after bilateral self-expandable metallic stent placement for malignant hilar biliary obstruction. Dig Endosc 2016; 28: 731-737

[2] Okuno M, Mukai T, Iwashita T et al. Evaluation of endoscopic reintervention for selfexpandable metallic stent obstruction after stent-in-stent placement for malignant hilar biliary obstruction. J Hepatobiliary Pancreat Sci 2019; 26: 211-218

[3] Kawakami H, Itoi T, Kuwatani M et al. Technical tips and troubleshooting of endoscopic biliary drainage for unresectable malignant hilar biliary obstruction. J Hepatobiliary Pancreat Sci 2015; 22: E12-E21

\section{Bibliography}

DOI https://doi.org/10.1055/a-1122-8350

Published online: 4.3.2020

Endoscopy 2020; 52: E330-E332

(c) Georg Thieme Verlag KG

Stuttgart · New York

ISSN 0013-726X

\section{ENDOSCOPY E-VIDEOS \\ https://eref.thieme.de/e-videos}

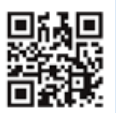

Endoscopy E-Videos is a free access online section, reporting on interesting cases and new techniques in gastroenterological endoscopy. All papers include a high quality video and all contributions are freely accessible online.

This section has its own submission website at https://mc.manuscriptcentral.com/e-videos 